\title{
Hydration of Atmospheric Molecular Clusters II: Organic Acid-Water Clusters
}

\author{
Kildgaard, Jens Vive; Mikkelsen, Kurt V.; Bilde, Merete ; Elm, Jonas
}

Published in:

Journal of Physical Chemistry Part A: Molecules, Spectroscopy, Kinetics, Environment and General Theory

Link to article, DOI:

10.1021/acs.jpca.8b07713

Publication date:

2018

Document Version

Peer reviewed version

Link back to DTU Orbit

Citation (APA):

Kildgaard, J. V., Mikkelsen, K. V., Bilde, M., \& Elm, J. (2018). Hydration of Atmospheric Molecular Clusters II: Organic Acid-Water Clusters. Journal of Physical Chemistry Part A: Molecules, Spectroscopy, Kinetics, Environment and General Theory, 142(43), 8549-8556. https://doi.org/10.1021/acs.jpca.8b07713

\section{General rights}

Copyright and moral rights for the publications made accessible in the public portal are retained by the authors and/or other copyright owners and it is a condition of accessing publications that users recognise and abide by the legal requirements associated with these rights.

- Users may download and print one copy of any publication from the public portal for the purpose of private study or research.

- You may not further distribute the material or use it for any profit-making activity or commercial gain

- You may freely distribute the URL identifying the publication in the public portal 
Subscriber access provided by DTU Library

\section{A: Spectroscopy, Molecular Structure, and Quantum Chemistry}

\section{Hydration of Atmospheric Molecular Clusters II: Organic Acid - Water Clusters} Jens Kildgaard, Kurt V. Mikkelsen, Merete Bilde, and Jonas Elm

J. Phys. Chem. A, Just Accepted Manuscript • DOI: 10.1021/acs.jpca.8b07713 • Publication Date (Web): 11 Oct 2018

Downloaded from http://pubs.acs.org on October 15, 2018

\section{Just Accepted}

"Just Accepted" manuscripts have been peer-reviewed and accepted for publication. They are posted online prior to technical editing, formatting for publication and author proofing. The American Chemical Society provides "Just Accepted" as a service to the research community to expedite the dissemination of scientific material as soon as possible after acceptance. "Just Accepted" manuscripts appear in full in PDF format accompanied by an HTML abstract. "Just Accepted" manuscripts have been fully peer reviewed, but should not be considered the official version of record. They are citable by the Digital Object Identifier (DOI®). "Just Accepted" is an optional service offered to authors. Therefore, the "Just Accepted" Web site may not include all articles that will be published in the journal. After a manuscript is technically edited and formatted, it will be removed from the "Just Accepted" Web site and published as an ASAP article. Note that technical editing may introduce minor changes to the manuscript text and/or graphics which could affect content, and all legal disclaimers and ethical guidelines that apply to the journal pertain. ACS cannot be held responsible for errors or consequences arising from the use of information contained in these "Just Accepted" manuscripts. 


\title{
Hydration of Atmospheric Molecular Clusters II: Organic Acid - Water Clusters
}

\author{
Jens Vive Kildgaard, ${ }^{\dagger}$ Kurt V. Mikkelsen,, , Merete Bilde, $\uparrow$ and Jonas Elm, ${ }^{*}, \S$ \\ Department of Energy Conversion and Storage, DTU Energy, Denmark, Department of \\ Chemistry, University of Copenhagen, Denmark, and Department of Chemistry and \\ iClimate, Aarhus University, Denmark \\ E-mail: kmi@chem.ku.dk; jelm@chem.au.dk
}

${ }^{*}$ To whom correspondence should be addressed

${ }^{\dagger}$ Technical University of Denmark

$\ddagger$ University of Copenhagen

$\mathbb{I}$ Aarhus University

$\S+4528938085$ 


\begin{abstract}
Using computational methods we study the gas phase hydration of three different atmospherically relevant organic acids with up to 10 water molecules. We study the dicarboxylic acid (pinic acid) and a tricarboxylic acid (3-methyl-1,2,3-butanetricarboxylic acid (mbtca)) that are both identified as products from $\alpha$-pinene oxidation reactions. We also study an 2-oxohexanediperoxy acid (ohdpa) that have been identified as a product from cyclohexene autoxidation. To sample the cluster structures, we employ our recently developed systematic hydrate sampling technique and identify a total of 551 hydrate clusters. The cluster structures and thermochemical parameters (at $298.15 \mathrm{~K}$ and $1 \mathrm{~atm})$ are obtained at the $\omega \mathrm{B} 97 \mathrm{X}-\mathrm{D} / 6-31++\mathrm{G}(\mathrm{d}, \mathrm{p})$ level of theory and the single point energy of the clusters have been refined using a high level DLPNO-CCSD(T)/augcc-pVTZ calculation. We find that all three tested organic acids interact significantly weaker with water compared to the primary nucleation precursor sulfuric acid. Even at $100 \%$ relative humidity (298.15 K and $1 \mathrm{~atm})$, we find that ohdpa remains unhydrated and only the monohydrate of pinic acid and mbtca are slightly populated (4\% and $2 \%$, respectively). From the obtained molecular structures potential implications for ice nucleating ability of aerosol particles is discussed.
\end{abstract}




\section{Introduction}

Atmospheric aerosol particles affect Earth's climate. Sun rays can be scattered by aerosol particles leading to a cooling of Earth's surface. ${ }^{1}$ Aerosol particles of roughly $50 \mathrm{~nm}$ or above can act as cloud condensation nuclei (CCN) enabling the formation of cloud droplets by water uptake and can change cloud microphysical properties, such as lifetime and precipitation. The formation and properties of clouds still linger as the largest uncertainty in current global climate models. Primary emitted particles such as desert dust and sea spray aerosols are often large enough to directly act as CCN. The formation of new particles around 1-2 nm sets the upper limit for the total number of particles in the atmosphere and the early growth determines the number of particles that survive to larger sizes relevant to act as CCN. ${ }^{2}$ The mechanism for formation of new particles is currently not well understood, but sulfuric acid, ${ }^{3}$ bases such as ammonia ${ }^{4}$ and amines ${ }^{5,6}$ are believed to be important constituents. The potential role of large organic molecules in new particle formation and subsequent growth is a topic of much current interest. Owing their low vapour pressure organic acids are important atmospheric species, as they presents some of the most likely compounds to be involved in the initial steps in forming new particles, ${ }^{7}$ as well as contributing to particle growth.

Formation of large biogenic organic acids in the atmosphere can for example be initiated by ozonolysis of $\alpha$-pinene, followed by consecutive reactions of the formed products with $\mathrm{OH}$ radicals. This can lead to dicarboxylic acid oxidation products such as cis-pinic acid (pa) ${ }^{8-10}$ and tricarboxylic acid oxidation products such as 3-methyl-1,2,3-butanetricarboxylic acid (mbtca). ${ }^{11,12}$ Figure 1 depicts the formed oxidation products pa and mbtca. While the absolute concentration of pinic acid and mbtca are difficult to assess in the ambient atmosphere, experimental studies have indicated that pinic acid and mbtca contributes $~ 3 \% 13$ and $0.61 \% 12$ of the total secondary organic aerosol mass, respectively. Furthermore, organic compounds with one or more carboxylic acid groups have been found to constitute on average $28 \%$ of secondary organic aerosol mass in the Northern Hemisphere. ${ }^{14}$

Highly oxygenated organic multifunctional (HOMs) compounds have also been specu- 
lated to be involved in the initial formation mechanism, ${ }^{15-18}$ but is primarily believed to be more important in the subsequent growth of the particles up to CCN sizes. ${ }^{19}$ However, presently there is very little information about the molecular structure of atmospheric HOMs originating from oxidation of biogenic volatile organic compounds such $\alpha$-pinene. ${ }^{20}$ Using cyclohexene $^{21}$ and methylcyclohexenes ${ }^{22}$ as a proxy for terpenes (such as $\alpha$-pinene), Rissanen et al. showed that HOMs with an oxygen-to-carbon ratio above one could be obtained from autoxidation. Figure 1 shows the molecular structure of one of the identified $\mathrm{C}_{6} \mathrm{H}_{8} \mathrm{O}_{7}$ oxidation products 2-oxohexanediperoxy acid (ohdpa). The ohdpa compound contains common functionalities found in HOMs such as carbonyl groups and peroxy groups. It can thereby be regarded as a proxy for larger molecular weight HOMs. However, it should be noted that albeit HOMs have a high oxygen-to-carbon ratio it does not necessarily implies that they have low vapour pressures. ${ }^{23}$

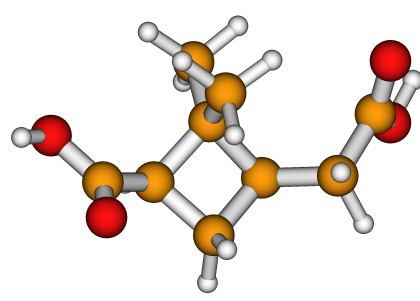

pa

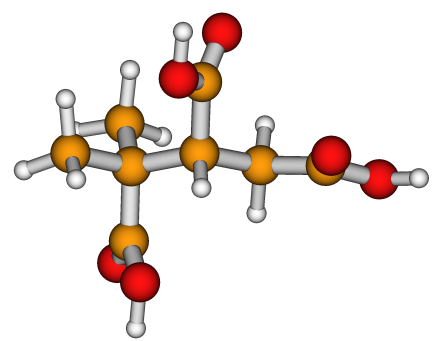

mbtca

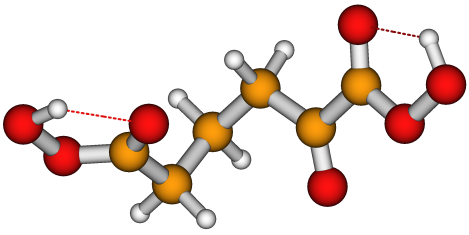

ohdpa

Figure 1: Molecular structure of pinic acid (pa), 3-methyl-1,2,3-butanetricarboxylic acid (mbtca) and 2-oxohexanediperoxy acid (ohdpa) optimized at the $\omega$ B97X-D/6-31++G(d,p) level of theory. Brown $=$ carbon, red = oxygen and grey $=$ hydrogen .

The presence of organic molecules, such as those in Figure 1, in aerosol particles changes the interaction with water molecules, influences hygroscopic growth, as well as important climate relevant particle properties such as light scattering, ${ }^{24}$ ability to act as $\mathrm{CCN}^{25,26}$ and ice nuclei in the atmosphere. ${ }^{27}$ However, very little is known about the molecular level mechanism for water vapour uptake and the effect of hydration on small molecular clusters consisting of organic compounds remain scarce. ${ }^{28-30}$ Quantum chemical studies can elucidate 


\section{Methods}

\subsection{Computational Details}

The optimization of cluster geometries and calculation of vibrational frequencies were performed using the Gaussian09 ${ }^{39}$ program. Configurational sampling of the hydrate cluster structures were performed using our recently reported systematic hydrate sampling technique. ${ }^{37}$ Water molecules are placed around all the exterior atoms in the molecule/cluster in different orientations, as well as adding interior water molecules to existing hydrogen bonds in the cluster. This is performed in a sequential manner, where one water molecule is added in each step. This generates around 1000-2000 initial conformations for each cluster, that were optimized using the semiempirical PM6 ${ }^{40}$ method. In each step of the PM6 calculation the vibrational frequencies were calculated (opt=calcall). Subsequently, a Boltzmann sorting was performed based on the Gibbs free energies and conformers with a population below $1 \%$ 
at $298.15 \mathrm{~K}$ and $1 \mathrm{~atm}$ were excluded. We utilized the $\omega \mathrm{B} 97 \mathrm{X}-\mathrm{D}^{41}$ functional to optimize the geometry and calculate the vibrational frequencies of the final cluster structures, as it has shown exceptionally good performance compared to other DFT functionals with the lowest errors compared to higher level $\operatorname{CCSD}(\mathrm{T})$ calculations for calculating binding energies of atmospheric molecular clusters. ${ }^{42-44}$ All the DFT calculations were performed using the 6-31++G(d,p) basis set, which has been shown to yield suitable performance compared to larger $6-311++\mathrm{G}(3 \mathrm{df}, 3 \mathrm{pd})^{45}$ and aug-cc-pV5Z ${ }^{46}$ basis sets for atmospherically relevant clusters. The single point energy of all the clusters have been calculated using a domain based pair natural orbital coupled cluster (DLPNO-CCSD $(\mathrm{T})^{47,48}$ ) calculation using an aug-ccpVTZ basis set in the ORCA program version 4.0.0. ${ }^{49}$ We used an aug-cc-pVTZ/C auxiliary basis set for density fitting and employed Coulomb and exchange fitting of the Hartree-Fock calculation with the auxiliary aug-cc-pVTZ/JK basis set. Calculations at the DLPNOCCSD(T)/aug-cc-pVTZ level of theory, has shown to yield results in good agreement with higher level explicitly correlated coupled cluster (CCSD(T)-F12/VDZ-F12) results for both the total $^{44}$ and relative ${ }^{37}$ binding energies of atmospheric molecular clusters. All the thermochemical parameters have been calculated at $298.15 \mathrm{~K}$ and $1 \mathrm{~atm}$, which correspond to ground level and lowest part of the troposphere conditions. We note that in all cases we will refer to the calculated Gibbs free energy, simply as the free energy. These conditions were chosen to better allow comparison with other studies. It should be noted that while we study the structural features in relation to ice formation, due to a relatively consistent entropy contribution for all the conformers the global minimum was found only to switch for the $(\text { mbtca })_{1}(\mathrm{w})_{4}$ cluster over the temperature range of $298.15 \mathrm{~K}$ to $273.15 \mathrm{~K}$. 


\section{Results and Discussion}

\section{1 (ohdpa $)_{1}(\mathbf{w})_{1-10}$ Cluster Structures}

Using our systematic hydrate sampling technique we obtained a total of 203 2-oxohexanediperoxy acid - water cluster structures. Figure 2 presents the ten lowest free energy cluster structures (298.15 K and $1 \mathrm{~atm})$ at the $\omega \mathrm{B} 97 \mathrm{X}-\mathrm{D} / 6-31++\mathrm{G}(\mathrm{d}, \mathrm{p})$ level of theory.

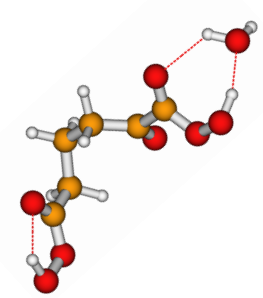

(ohdpa) $)_{1}(w)_{1}$

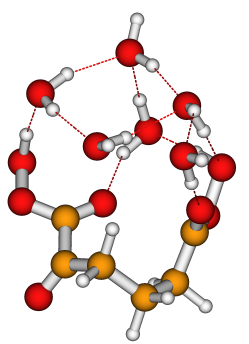

(ohdpa) ${ }_{1}(w)_{6}$

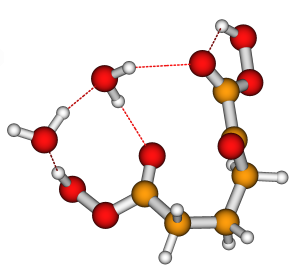

(ohdpa) $)_{1}(w)_{2}$
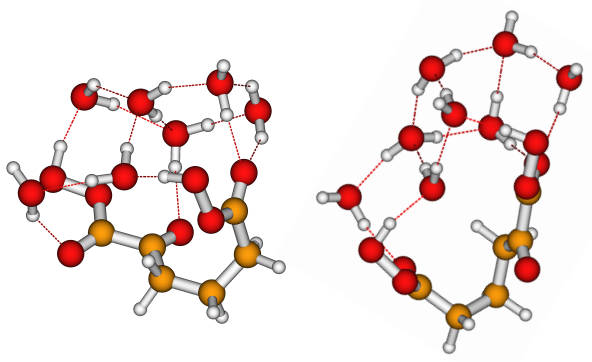

(ohdpa) $)_{1}(w)_{7}$

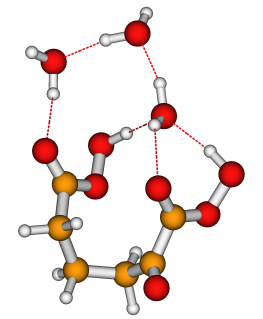

(ohdpa) $)_{1}(w)_{3}$

(ohdpa) ${ }_{1}(w)_{8}$

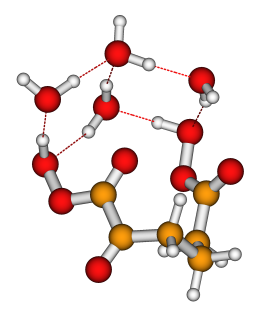

$(\text { ohdpa })_{1}(w)_{4} \quad(\text { ohdpa })_{1}(w)_{5}$

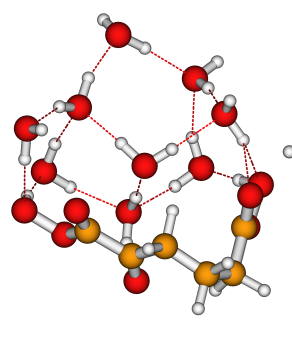

(ohdpa) $)_{1}(w)_{9}$
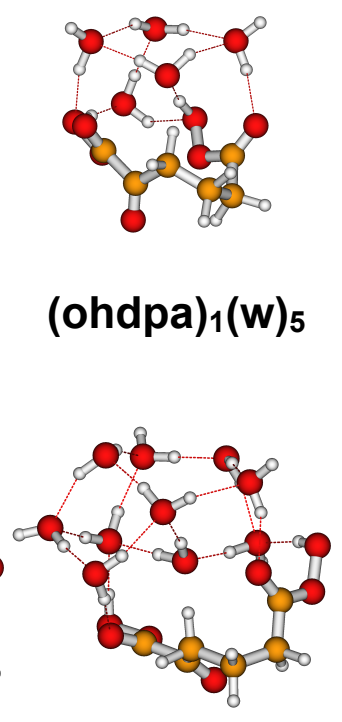

(ohdpa) $)_{1}(w)_{10}$

Figure 2: 2-oxohexanediperoxy acid clusters: Molecular structure of the identified ten lowest free energy (ohdpa) $)_{1}(\mathrm{w})_{1-10}$ clusters, at $298.15 \mathrm{~K}$ and $1 \mathrm{~atm}$, optimized at the $\omega \mathrm{B} 97 \mathrm{X}-\mathrm{D} / 6-$ $31++\mathrm{G}(\mathrm{d}, \mathrm{p})$ level of theory.

Due to the flexible backbone of the ohdpa compound the water molecules interact with both peroxy acid moieties when two or more water molecules are present in the cluster. As more water molecules are added the hydrogen bond network is increased and it is observed that the peroxy acid groups participate both as hydrogen bond donors and acceptors in the cluster. Adding more water molecules to the cluster is seen to relax the carbon backbone of the ohdpa compound, such that it is almost linear in the (ohdpa $)_{1}(\mathrm{w})_{9-10}$ clusters, compared to the bend backbone in the (ohdpa $)_{1}(\mathrm{w})_{2-8}$ clusters. Only the (ohdpa $)_{1}(\mathrm{w})_{5}$ cluster is 
observed to form a cube-like orientation of water molecules, involving both the peroxy acid groups of ohdpa. In the remaining clusters the water molecules are seen to form cage-like geometries, with no distinct structural features.

\section{$3.2(\mathbf{p a})_{1}(\mathrm{w})_{1-10}$ Cluster Structures}

A total of 204 pinic acid - water cluster structures were identified. Figure 3 shows the obtained ten lowest free energy cluster structures (298.15 K and $1 \mathrm{~atm})$, at the $\omega$ B97X$\mathrm{D} / 6-31++\mathrm{G}(\mathrm{d}, \mathrm{p})$ level of theory. The two acid groups in pinic acid have been labelled acid group 1 and 2. These two groups differ by the carbon chain length, such that acid group 1 is directly attached to the four membered ring on pinic acid, while acid group 2 has an additional carbon atom linker in between. While these are minor structural differences it has previously been shown that the interaction between pinic acid and sulfuric acid, preferably occur at acid group 1.
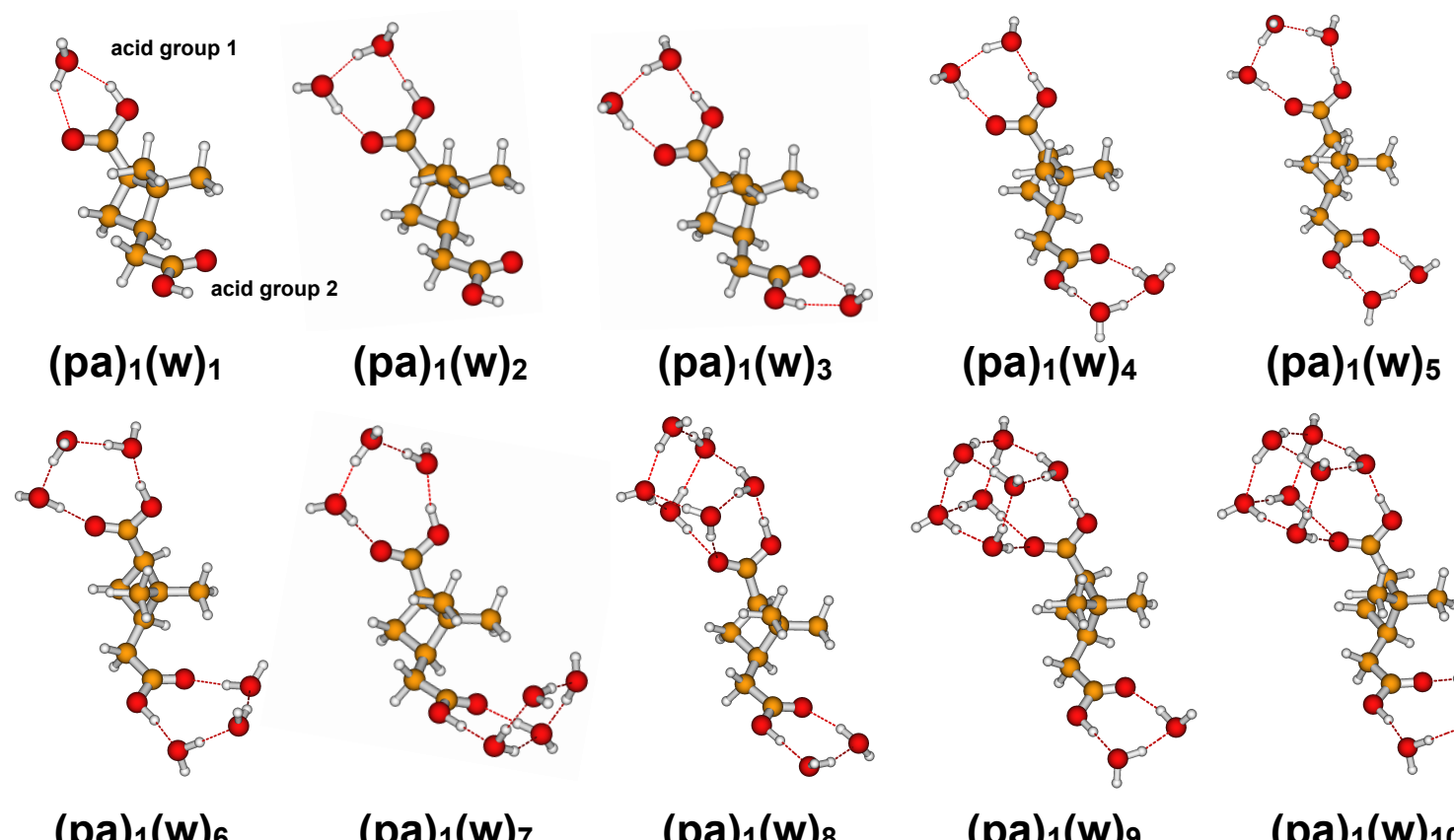
Compared to the ohdpa compound pinic acid is more rigid due to the four-membered ring in the carbon backbone. This implies that the water molecules predominantly will interact with one of the two available carboxylic acid groups (see Figure 1), as interacting with both acid groups simultaneously would yield a large strain in the rigid carbon backbone. In the lowest free energy cluster structures we do not observe any bridging between the two groups. This implies that more than 10 water molecules would be required to efficiently bridge between the two groups.

The first two water molecules preferably interact with acid group 1. The conformation where one water molecule is residing at each carboxylic acid group is found to be $2.0 \mathrm{kcal} / \mathrm{mol}$ higher in free energy. This is consistent with our previous study of pinic acid - sulfuric acid clusters, where acid group 1 also preferably interacted with sulfuric acid ${ }^{50}$ compared to acid group 2. The third water molecule is found to interact with the vacant carboxylic acid group 2, compared to participating in a larger hydrogen bond network at carboxylic acid group 1. The fifth water molecule interacts with acid group 1, extending the hydrogen bonded network to three water molecules. In the same manner the sixth water molecule extend the water hydrogen bonded network to three at group 2. The conformation where four water molecules are residing at acid group 1, is found to be $2.0 \mathrm{kcal} / \mathrm{mol}$ higher in free energy. Interestingly, we find that the $(\mathrm{pa})_{1}(\mathrm{w})_{7}$ cluster has four water molecules at acid group 2 instead of acid group 1. The $(\mathrm{pa})_{1}(\mathrm{w})_{7}$ cluster, where the four water is residing at acid group 1 is found to be $1.3 \mathrm{kcal} / \mathrm{mol}$ higher in free energy than the lowest free energy structure. This difference in free energy is primarily caused by differences in the thermal contribution to the free energy, as the two conformations have very similar electronic binding energy, within $0.1 \mathrm{kcal} / \mathrm{mol}$ of each other. The lowest free energy $(\mathrm{pa})_{1}(\mathrm{w})_{8}$ cluster is seen to have six water molecules interacting with acid group 1, with two interacting with acid group 2. Similarly, (pa) $)_{1}(\mathrm{w})_{9}$ have seven water molecules interacting with acid group 1, with the remaining two interacting with acid group 2. Interestingly, it is more favourable to have three water molecules at acid group 2 in the $(\mathrm{pa})_{1}(\mathrm{w})_{10}$ cluster compared to increasing the amount of water molecules to 
eight at acid group 1.

For the larger $(\mathrm{pa})_{1}(\mathrm{w})_{8-10}$ cluster structures cube-like hydrogen bonded networks of 6-7 water molecules is observed. In the $(\mathrm{pa})_{1}(\mathrm{w})_{9}$ and $(\mathrm{pa})_{1}(\mathrm{w})_{10}$ clusters, cubes consisting of 7 water molecules interact via hydrogen bonding both to the donor and acceptor of the carboxylic acid group. However, we do not observe any cyclic six-membered structures, which is what one would expect to initiate the formation of $I_{h}$ ice crystal structures.

\section{$3.3 \quad(\text { mbtca })_{1}(w)_{1-10}$ Cluster Structures}

We identified a total of 144 3-methyl-1,2,3-butanetricarboxylic acid - water cluster structures. Figure 4 shows the obtained ten lowest free energy cluster structures (298.15 K and $1 \mathrm{~atm}$ ), at the $\omega \mathrm{B} 97 \mathrm{X}-\mathrm{D} / 6-31++\mathrm{G}(\mathrm{d}, \mathrm{p})$ level of theory.

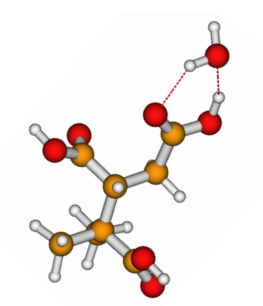

$(\text { mbtca })_{1}(w)_{1}$

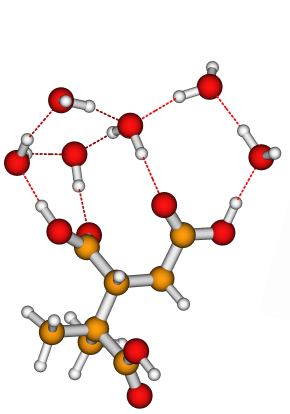

(mbtca) $)_{1}(w)_{6}$

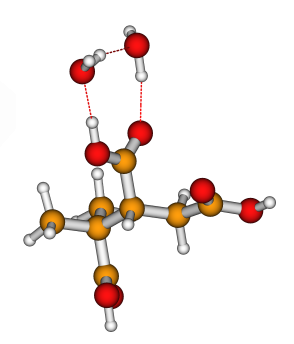

$(\text { mbtca })_{1}(w)_{2}$

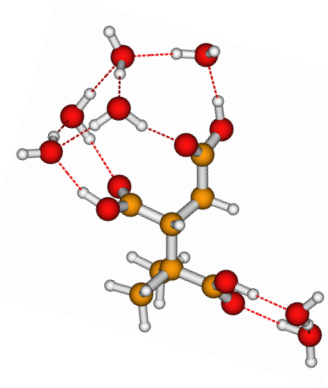

$(\text { mbtca })_{1}(w)_{7}$

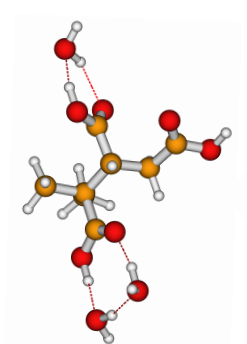

(mbtca) $)_{1}(w)_{3}$

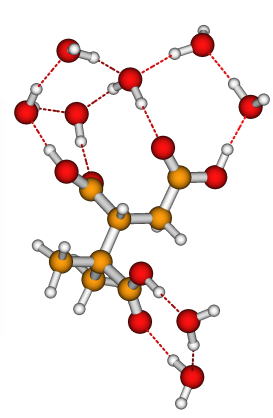

$(\text { mbtca })_{1}(w)_{8}$

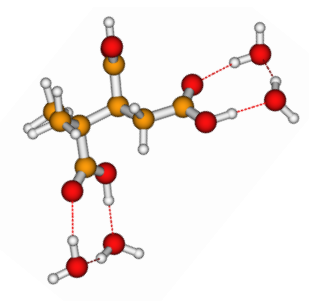

$(\text { mbtca })_{1}(w)_{4}$

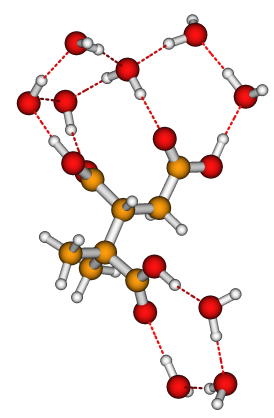

(mbtca) $)_{1}(w)_{9}$

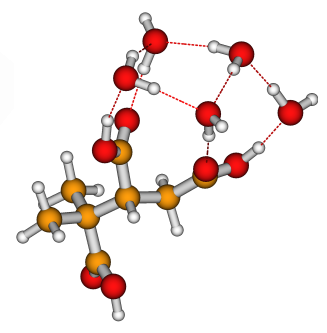

$(\text { mbtca })_{1}(w)_{5}$

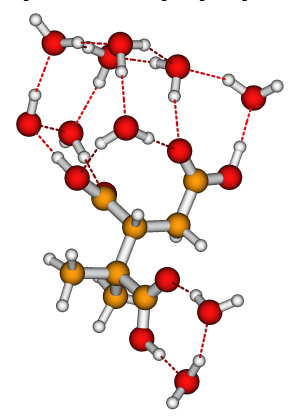

(mbtca) $)_{1}(w)_{10}$

Figure 4: 3-methyl-1,2,3-butanetricarboxylic acid clusters: Molecular structure of the identified ten lowest free energy $(\mathrm{mbtca})_{1}(\mathrm{w})_{1-10}$ clusters, at $298.15 \mathrm{~K}$ and $1 \mathrm{~atm}$, optimized at the $\omega \mathrm{B} 97 \mathrm{X}-\mathrm{D} / 6-31++\mathrm{G}(\mathrm{d}, \mathrm{p})$ level of theory.

Mbtca has an additional carboxylic acid moiety compared to pinic acid, as well as having a flexible carbon backbone structure. In a similar manner to pinic acid it is found that it is 
more favourable to have two water molecules residing at one carboxylic acid group instead of distributing them between different groups. This is observed also for the $(\text { mbtca })_{1}(\mathrm{w})_{4}$ cluster where two water molecules reside at two different carboxylic acid groups. It should be noted that at lower temperature $(293.15 \mathrm{~K} \text { and below), the (mbtca) })_{1}(\mathrm{w})_{4}$ conformer shown in Figure 4 is only the second lowest in free energy. A conformer where four water molecules are bridging two carboxylic acid groups is found to be the lowest in free energy at $293.15 \mathrm{~K}$. The relative population $\left(p_{i}\right)$ of a given conformer $i$ is given by:

$$
p_{i}=\frac{\exp \left(-\frac{\Delta \Delta G_{i}}{R T}\right)}{\sum_{j} \exp \left(-\frac{\Delta \Delta G_{j}}{R T}\right)}
$$

Here $\Delta \Delta G_{i}$ is the relative free energy of conformer $i$ and the sum runs over all conformers $j$. The relative population of the lowest five $(\text { mbtca })_{1}(\mathrm{w})_{4}$ conformers are shown in Figure 5.

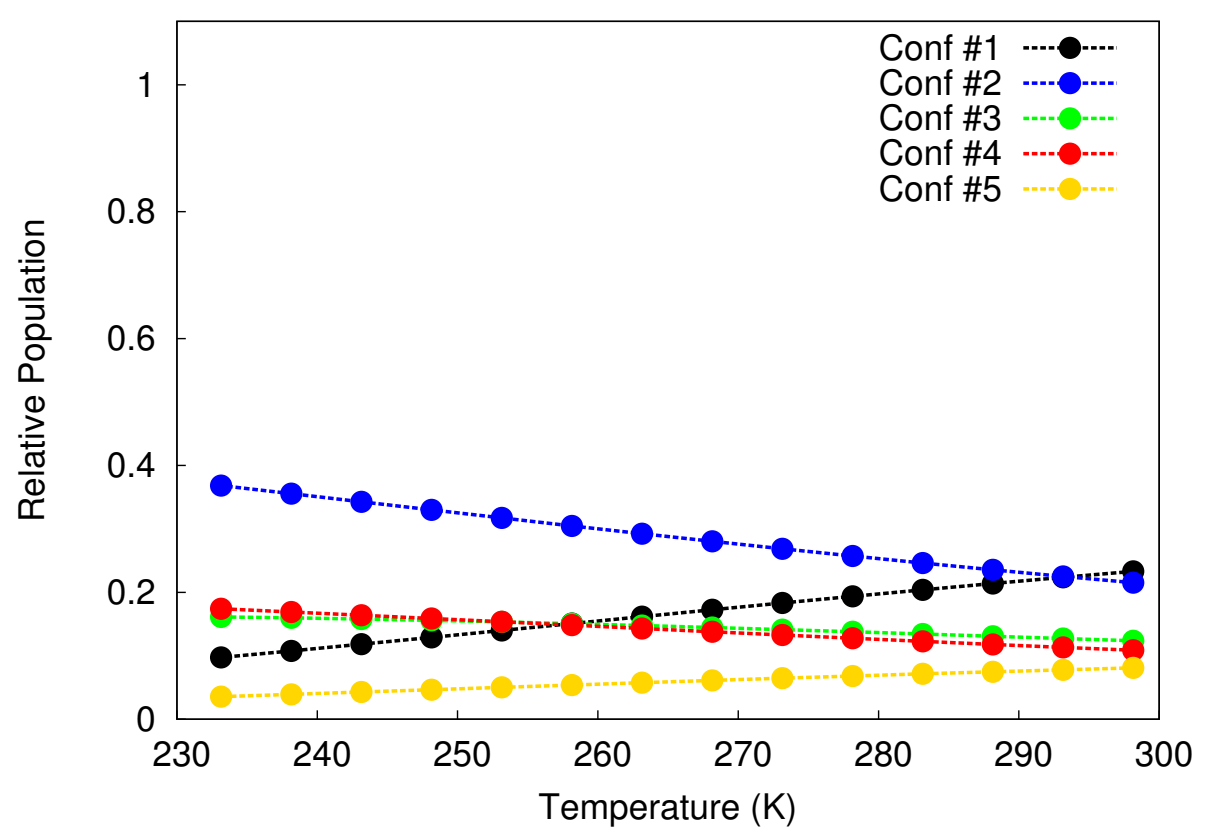

Figure 5: Calculated relative populations $\left(p_{i}\right)$ of the different (mbtca $)_{1}(\mathrm{w})_{4}$ cluster conformations as a function of temperature $(K)$.

It is seen that the $(\mathrm{mbtca})_{1}(\mathrm{w})_{4}$ conformers show different temperature dependence. Con- 
former \#1 and \#5, both have two water molecules residing at two different acid groups, while the conformers \#2-4 have the four water molecules bridging between two acid groups. It is seen at lower temperature $(258.15 \mathrm{~K}$ or below), that the bridged structures have the highest populations. This clearly indicates that the populations of the clusters yield more ordered structures at lower temperatures.

In contrast to the pinic acid - water clusters, the flexible backbone allows for bridging between two of the carboxylic acid groups with five or more water molecules in the cluster. The (mbtca $)_{1}(\mathrm{w})_{6}$ cluster forms a network of six water molecules shared between two carboxylic acid groups. A ring of four water molecules is formed via interaction between one of the acid groups of mbtca, as well as interacting with the $\mathrm{C}=\mathrm{O}$ group at another acid group. The remaining $\mathrm{OH}$ group forms a hydrogen bonded network with the remaining two water molecules, that further stabilize the ring consisting of four water molecules via secondary interactions. This orientation of water molecules is found to be particularly stable, as it exists in the $(\mathrm{mbtca})_{1}(\mathrm{w})_{8}$ and $(\mathrm{mbtca})_{1}(\mathrm{w})_{9}$ cluster structures as well. In the (mbtca $)_{1}(\mathrm{w})_{9}$ cluster it is even found that it is more favourable to form a network of four hydrogen bonds at the third acid group, compared to breaking up interaction between the six water molecules and the two other acid groups. In the $(\mathrm{mbtca})_{1}(\mathrm{w})_{10}$ cluster a large cage-like structure consisting of two layers of pseudo 5-membered rings is found. The ring structure is stabilized by one additional water molecule at the periphery. This indicates that flexible organic compounds containing multiple carboxylic acid groups are capable of promoting layered water structures. However, in no cases are six-membered ring structures formed.

\subsection{Thermochemistry}

The previous three sections outlined the structural features of the identified acid - water clusters. To assess whether a given cluster hydrate is formed under ambient conditions, we 
calculate the step-wise reaction free energies for adding the $n^{\prime} t h$ water molecule:

$$
\Delta G_{\text {water,add }}=\Delta G_{n}-\Delta G_{n-1}
$$

The stepwise reaction free energy $\left(\Delta G_{\text {water,add }}\right)$ for the studied clusters are presented in Table 1 at the DLPNO-CCSD(T)/aug-cc-pVTZ// $\omega$ B97X-D/6-31++G(d,p) level of theory, at $298.15 \mathrm{~K}$ and $1 \mathrm{~atm}$. The data for sulfuric acid is taken from ref. ${ }^{37}$

Table 1: Stepwise reaction free energy $\left(\Delta G_{\text {water,add }}\right.$ in $\left.\mathrm{kcal} / \mathrm{mol}\right)$ for adding water molecules to the clusters. Calculated at $298.15 \mathrm{~K}$ and 1 atm.

\begin{tabular}{cccccc}
\hline \hline$n$ & sa & ohdpa & pa & mbtca & water \\
\hline \hline 1 & -1.7 & 4.2 & -0.2 & 0.4 & - \\
2 & -1.0 & 0.4 & -0.2 & -0.1 & 4.5 \\
3 & -1.1 & 0.1 & 1.2 & 0.5 & 2.3 \\
4 & -1.1 & 1.2 & 0.3 & -0.3 & 0.0 \\
5 & 1.6 & 0.9 & 0.8 & 1.7 & 1.5 \\
6 & 0.2 & 0.7 & -0.2 & 0.4 & 5.5 \\
7 & -0.1 & 2.2 & 3.4 & 0.7 & 0.7 \\
8 & 0.3 & 0.0 & 2.3 & -1.0 & 0.0 \\
9 & 0.1 & 2.1 & 0.0 & 1.5 & 0.9 \\
10 & -0.4 & 0.5 & 0.3 & 1.6 & 1.7
\end{tabular}

The reaction free energy for the first addition of a water molecule to the organic acids is seen to be $4.2,-0.2$ and $0.4 \mathrm{kcal} / \mathrm{mol}$ for ohdpa, pa and mbtca, respectively. The reaction free energy for adding a water molecule to sulfuric acid is more favourable with a value of $-1.7 \mathrm{kcal} / \mathrm{mol}$. In comparison, the formation free energy of the water dimer is higher than

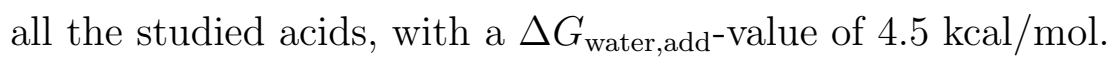

The extent that the clusters are hydrated under atmospheric conditions can be investigated using simple equilibrium calculations. The relative population $x_{n}$ of a given hydrate 
$n$, can be calculated as: ${ }^{51}$

$$
x_{n}=\left(\frac{p\left(\mathrm{H}_{2} \mathrm{O}\right)}{p_{\text {ref }}}\right)^{n} x_{0} \exp \left(-\frac{\Delta G_{n}}{R T}\right)
$$

Here $\Delta G_{n}$ is the binding free energy of the cluster, $p_{\text {ref }}$ is the reference pressure (1 atm). The population of the dry cluster $x_{0}$ is chosen such that all the populations sum up to unity. $p\left(\mathrm{H}_{2} \mathrm{O}\right)=0.0316$ atm is the saturation water vapour pressure, at $298.15 \mathrm{~K}$. Figure 6 presents the calculated hydrate distributions $\left(x_{n}\right)$ at $20 \%, 40 \%, 60 \%, 80 \%$ and $100 \%$ relative humidity.
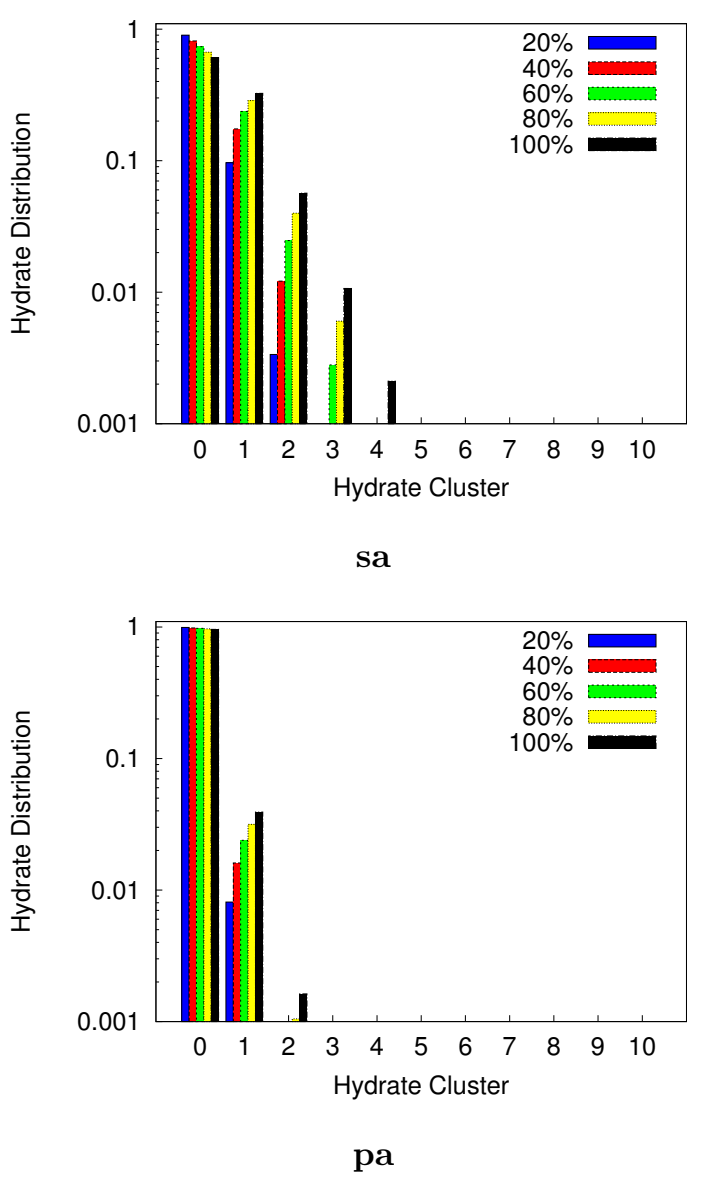
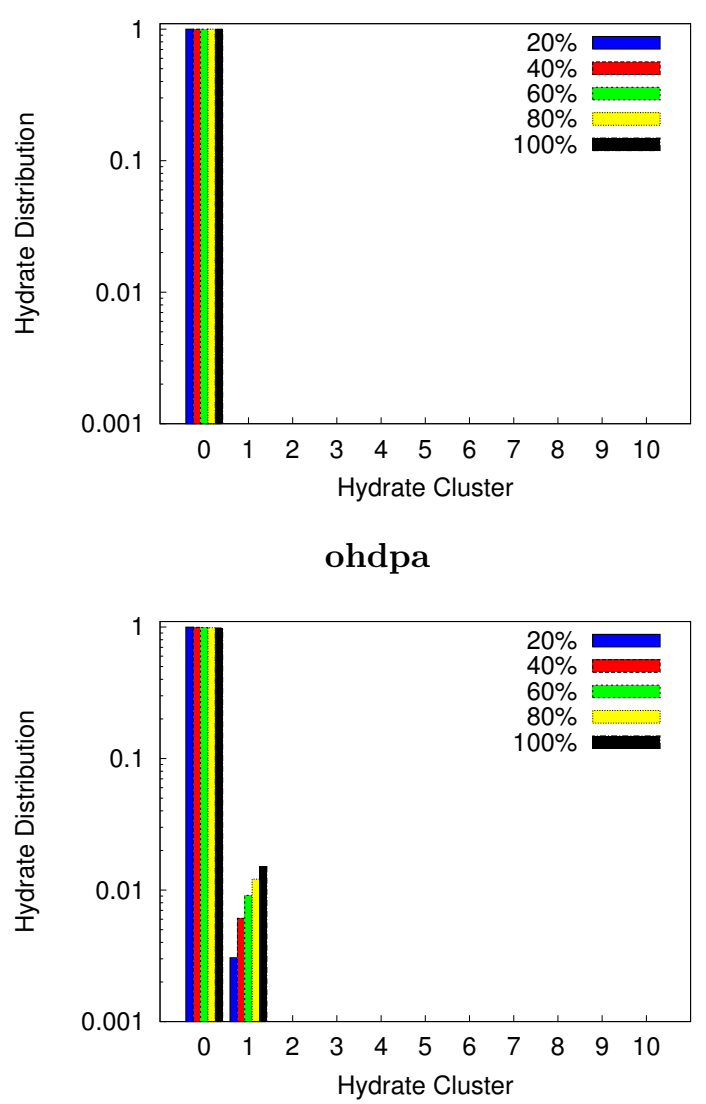

mbtca

Figure 6: Calculated hydrate distributions $\left(x_{n}\right)$ of the $(\text { acid })_{1}(\mathrm{w})_{1-10}$ clusters, with acid $=$ sa, ohdpa, pa and mbtca at relative humidity of $20 \%, 40 \%, 60 \%, 80 \%$ and $100 \%$. Calculations are performed at $298.15 \mathrm{~K}$ and $1 \mathrm{~atm}$. Note the logarithmic scale on the y-axis. 
It is seen that sulfuric acid is predominantly unhydrated at low relative humidity, with the emergence of the mono- and di-hydrates with populations of $32 \%$ and $6 \%$, respectively, at $100 \%$ relative humidity. Due to the very weak interaction between peroxy acid groups and water, ohdpa is in all cases found not to be hydrated. It is to be expected that ohdpa interacts weakly with water, as the peroxy acid groups form intramolecular hydrogen bonds, that need to be broken before the compound can interact with water. This is consistent with our previous study of ohdpa - sulfuric acid clusters. ${ }^{52,53}$ This could indicate that HOMs that mainly consist of peroxy acid groups are not significantly contributing to the hygroscopicity of atmospheric aerosols. At low relative humidity pa and mbtca is also found not to be hydrated to any significant extent. At $100 \%$ relative humidity the populations of the pa and mbtca monohydrate reach $4 \%$ and $2 \%$, respectively. These findings suggests, that the studied organic acids are not significantly hydrated in the ambient atmosphere.

\subsection{Comparison between DFT and DLPNO Binding Energies}

Density functional theory calculations, especially with a small basis set, is known to overestimate the binding free energy compared to higher level methods. ${ }^{43}$ The calculated binding free energies of the studied clusters at the $\omega \mathrm{B} 97 \mathrm{X}-\mathrm{D} / 6-31++\mathrm{G}(\mathrm{d}, \mathrm{p})$ level of theory are shown in the Supporting Information. Figure 7 presents the electronic binding energy of the (ohdpa) $)_{1}\left(\mathrm{H}_{2} \mathrm{O}\right)_{1-10}$ clusters calculated using $\omega \mathrm{B} 97 \mathrm{X}-\mathrm{D} / 6-31++\mathrm{G}(\mathrm{d}, \mathrm{p})$ and DLPNOCCSD(T)/aug-cc-pVTZ. We previously identified that a simple scaling of the $\omega$ B97X-D/6$31++\mathrm{G}(\mathrm{d}, \mathrm{p})$ electronic binding energy by a factor of 0.84544 significantly improved the agreement with the DLPNO results for $\left(\mathrm{H}_{2} \mathrm{SO}_{4}\right)_{1}\left(\mathrm{H}_{2} \mathrm{O}\right)_{1-15}$ clusters. ${ }^{37}$ Similar figures for the $(\mathrm{pa})_{1}\left(\mathrm{H}_{2} \mathrm{O}\right)_{1-10}$ and $(\mathrm{mbtca})_{1}\left(\mathrm{H}_{2} \mathrm{O}\right)_{1-10}$ clusters are presented in the Supporting Information. 


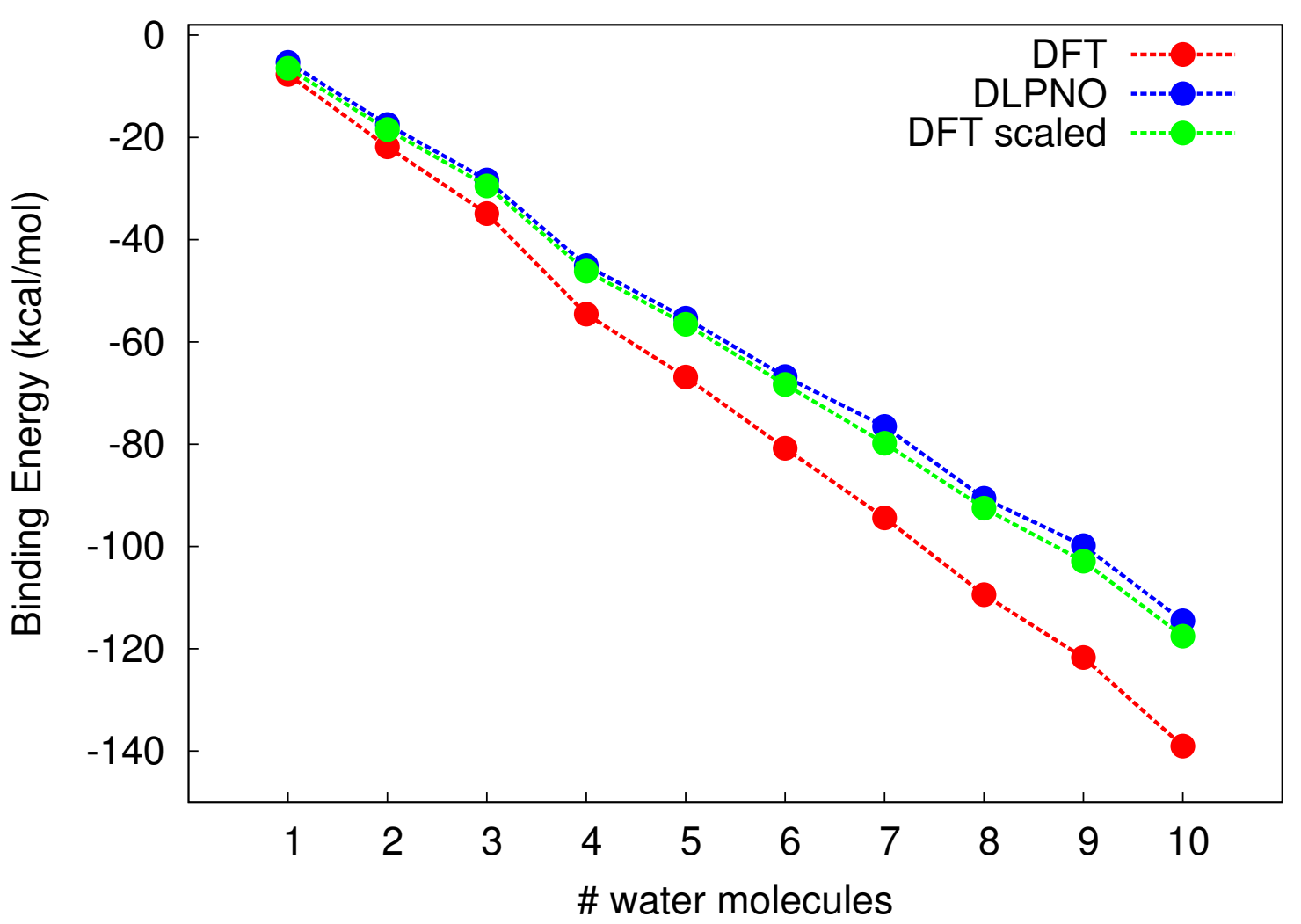

Figure 7: Calculated electronic binding energies in $\mathrm{kcal} / \mathrm{mol}$ of the (ohdpa $)_{1}(\mathrm{w})_{1-10}$ clusters using $\omega$ B97X-D/6-31++G(d,p) $(\cdots \bullet \cdots)$, DLPNO-CCSD $(\mathrm{T}) /$ aug-cc-pVTZ $(\cdots \bullet \cdots)$ and $\omega \mathrm{B} 97 \mathrm{X}-\mathrm{D} / 6-31++\mathrm{G}(\mathrm{d}, \mathrm{p})$ scaled by a factor of $0.84544(\cdots \bullet \cdots)$.

In accordance with our previous study of $\left(\mathrm{H}_{2} \mathrm{SO}_{4}\right)_{1}\left(\mathrm{H}_{2} \mathrm{O}\right)_{1-15}$ clusters, the $\omega$ B97X-D/6$31++\mathrm{G}(\mathrm{d}, \mathrm{p})$ level of theory, yield severely overestimated binding energies compared to DLPNO. However, it should be noted that even though the values are overestimated, the correct trend is obtained. Applying the simple scaling factor of 0.84544 obtained for the $\left(\mathrm{H}_{2} \mathrm{SO}_{4}\right)_{1}\left(\mathrm{H}_{2} \mathrm{O}\right)_{1-15}$ clusters, significantly improves the calculated binding energies compared to the DLPNO results. It should be noted that the application of the scaling factor is only valid for the electronic energies and not for the Gibbs free energies. This is consistent with the calculations performed on the $(\mathrm{pa})_{1}\left(\mathrm{H}_{2} \mathrm{O}\right)_{1-10}$ and (mbtca $)_{1}\left(\mathrm{H}_{2} \mathrm{O}\right)_{1-10}$ clusters (see Supporting Information). This finding indicates that the obtained scaling factor can be used both for hydrated systems containing organic acids, as well as sulfuric acid, and yield an efficient approach to improve the binding energies in cases where DLPNO-CCCSD(T) 
calculations are not possible.

\section{4 - Conclusions}

We have studied the gas phase hydration of three organic acids of atmospheric relevance. We demonstrate that our recently published hydrate sampling technique can be utilized for complicated systems containing multiple functional groups. As the organic acids do not aid in the formation of cyclic six membered water cluster structures, which is what one would expect to initiate the formation of $\mathrm{I}_{\mathrm{h}}$ ice crystal structures, it is unlikely that a single acids can facilitate ice nucleation at the interface of particles. A larger network of functional groups is most likely important.

We find that the organic acids are not hydrated to any significant extent at ambient atmospheric conditions. For sulfuric acid both the mono- and di-hydrate are slightly populated at atmospheric conditions. To fully understand whether there is any synergetic effect between sulfuric acid and organic acid in promoting water uptake on clusters, larger clusters consisting of all three components should be studied in further detail.

\section{Acknowledgement}

J.E thanks the Villum foundation for financial support and K.V.M. thanks University of Copenhagen for financial support. We thank the Danish e-Infrastructure Cooperation (DeiC) for computational resources.

\section{Supporting Information Available}

The following is available as supporting information: xyz-files of the studied molecular structures at the $\omega \mathrm{B} 97 \mathrm{X}-\mathrm{D} / 6-31++\mathrm{G}(\mathrm{d}, \mathrm{p})$ level of theory. Figures comparing the DLPNO$\operatorname{CCSD}(\mathrm{T})$ binding energies with $\omega \mathrm{B} 97 \mathrm{X}-\mathrm{D} / 6-31++\mathrm{G}(\mathrm{d}, \mathrm{p})$ for the $(\mathrm{pa})_{1}(\mathrm{w})_{1-10}$ and $(\mathrm{mbtca})_{1}(\mathrm{w})_{1-10}$ cluster systems. This material is available free of charge via the Internet at http: 
//pubs.acs.org/.

\section{References}

(1) Haywood, J.; Boucher, O. Estimates of the Direct and Indirect Radiative Forcing due to Tropospheric Aerosols: A Review. Rev. Geophys. 2000, 38, 513-543.

(2) Pierce, J. R.; Adams, P. J. Uncertainty in Global CCN Concentrations from Uncertain Aerosol Nucleation and Primary Emission Rates. Atmos. Chem. Phys. 2009, 9, 13391356.

(3) Sipilä, M.; Berndt, T.; Petäjä, T.; Brus, D.; Vanhanen, J.; Stratmann, F.; Patokoski, J.; Mauldin, R. L.; Hyvrinen, A.-P.; Lihavainen, H. et al. The Role of Sulfuric Acid in Atmospheric Nucleation. Science 2010, 327, 1243-1246.

(4) Kirkby, J.; Curtius, J.; Almeida, J.; Dunne, E.; Duplissy, J.; Ehrhart, S.; Franchin, A.; Gagne, S.; Ickes, L.; Krten, A. et al. Role of Sulphuric Acid, Ammonia and Galactic Cosmic Rays in Atmospheric Aerosol Nucleation. Nature 2011, 476, 429 - 433.

(5) Kurtén, T.; Loukonen, V.; Vehkamäki, H.; Kulmala, M. Amines are Likely to Enhance Neutral and Ion-induced Sulfuric Acid-water Nucleation in the Atmosphere More Effectively than Ammonia. Atmos. Chem. Phys. 2008, 8, 4095-4103.

(6) Ortega, I. K.; Kupiainen, O.; Kurtén, T.; Olenius, T.; Wilkman, O.; McGrath, M. J.; Loukonen, V.; Vehkamäki, H. From Quantum Chemical Formation Free Energies to Evaporation Rates. Atmos. Chem. Phys. 2012, 12, 225-235.

(7) Elm, J.; Myllys, N.; Kurtén, T. What is Required for Highly Oxidized Molecules to Form Clusters with Sulfuric Acid? J. Phys. Chem. A. 2017, 121, 4578-4587.

(8) Christoffersen, T.; Hjorth, J.; Horie, O.; Jensen, N.; Kotzias, D.; Molander, L. L.; Neeb, P.; Ruppert, L.; Winterhalter, R.; Virkkula, A. et al. Cis-Pinic Acid, a Possible 
Precursor for Organic Aerosol Formation from Ozonolysis of $\alpha$-Pinene. Atmos. Environ. 1998, 32, $1657-1661$.

(9) Koch, S.; Winterhalter, R.; Uherek, E.; Kollo, A.; Neeb, P.; Moortgat, G. K. Formation of New Particles in the Gas-phase Ozonolysis of Monoterpenes. Atmos. Environ. 2000, 34, 4031-4042.

(10) Jenkin, M. E.; Shallcross, D. E.; Harvey, J. N. Development and Application of a Possible Mechanism for the Generation of Cis-Pinic Acid from the Ozonolysis of Alphaand Beta-Pinene. Atmos. Environ. 2000, 34, 2837-2850.

(11) Szmigielski, R.; Surratt, J. D.; Gómez-González, Y.; Van der Veken, P.; Kourtchev, I.; Vermeylen, R.; Blockhuys, F.; Jaoui, M.; Kleindienst, T. E.; Lewandowski, M. et al. 3methyl-1,2,3-butanetricarboxylic Acid: An Atmospheric Tracer for Terpene Secondary Organic Aerosol. Geophys. Res. Lett. 2007, 34, L24811.

(12) Müller, L.; Reinnig, M.; Naumann, K. H.; Saathoff, H.; Mentel, T. F.; Donahue, N. M.; Hoffmann, T. Formation of 3-methyl-1,2,3-butanetricarboxylic Acid via Gas Phase Oxidation of Pinonic Acid - A Mass Spectrometric Study of SOA Aging. Atmos. Chem. Phys. 2012, 12, 1483-1496.

(13) Kristensen, K.; Watne, Å. K.; Hammes, J.; Lutz, A.; Petäjä, T.; Hallquist, M.; Bilde, M.; Glasius, M. High-Molecular Weight Dimer Esters Are Major Products in Aerosols from $\alpha$-Pinene Ozonolysis and the Boreal Forest. Environ. Sci. Technol. Lett. 2016, 3, 280-285.

(14) Yatavelli, R. L. N.; Mohr, C.; Stark, H.; Day, D. A.; Thompson, S. L.; LopezHilker, F. D.; Campuzano-Jost, P.; Palm, B. B.; Vogel, A. L.; Hoffmann, T. et al. Estimating the Contribution of Organic Acids to Northern Hemispheric Continental Organic Aerosol. Geophys. Res. Lett. 2015, 42, 6084-6090. 
(15) Metzger, A.; Verheggen, B.; Dommen, J.; Duplissy, J.; Prevot, A. S. H.; Weingartner, E.; Riipinen, I.; Kulmala, M.; Spracklen, D. V.; Carslaw, K. S. et al. Evidence for the Role of Organics in Aerosol Particle Formation under Atmospheric Conditions. PNAS 2010, 10\%, 6646-6651.

(16) Schobesberger, S.; Junninen, H.; Bianchi, F.; Lönn, G.; Ehn, M.; Lehtipalo, K.; Dommen, J.; Ehrhart, S.; Ortega, I. K.; Franchin, A. et al. Molecular Understanding of Atmospheric Particle Formation from Sulfuric Acid and Large Oxidized Organic Molecules. Proc. Natl. Acad. Sci. U.S.A. 2013, 110, 17223-17228.

(17) Riccobono, F.; Schobesberger, S.; Scott, C. E.; Dommen, J.; Ortega, I. K.; Rondo, L.; Almeida, J.; Amorim, A.; Bianchi, F.; Breitenlechner, M. et al. Oxidation Products of Biogenic Emissions Contribute to Nucleation of Atmospheric Particles. Science 2014, $344,717-721$.

(18) Ehn, M.; Thornton, J. A.; Kleist, E.; Sipilä, M.; Junninen, H.; Pullinen, I.; Springer, M.; Rubach, F.; Tillmann, R.; Lee, B. et al. A Large Source of Low-Volatility Secondary Organic Aerosol. Nature 2014, 506, 476-479.

(19) Tröstl, J.; Chuang, W. K.; Gordon, H.; Heinritzi, M.; Yan, C.; Molteni, U.; Ahlm, L.; Frege, C.; Bianchi, F.; Wagner, R. et al. The Role of Low-volatility Organic Compounds in Initial Particle Growth in the Atmosphere. Nature 2016, 533, 527-531.

(20) Kurtén, T.; Rissanen, M. P.; Mackeprang, K.; Thornton, J. A.; Hyttinen, N.; Jørgensen, S.; Kjaergaard, H. G. Computational Study of Hydrogen Shifts and RingOpening Mechanisms in $\alpha$ Pinene Ozonolysis Products. J. Phys. Chem. A. 2015, 119, $11366-11375$.

(21) Rissanen, M. P.; Kurtén, T.; Sipilä, M.; Thornton, J. A.; Kangasluoma, J.; Sarnela, N.; Junninen, H.; Jørgensen, S.; Schallhart, S.; Kajos, M. K. et al. The Formation of 
Highly Oxidized Multifunctional Products in the Ozonolysis of Cyclohexene. J. Am. Chem. Soc. 2014, 136, 15596-15606.

(22) Rissanen, M. P.; Kurtén, T.; Sipilä, M.; Thornton, J. A.; Kausiala, O.; Garmash, O.; Kjaergaard, H. G.; Petäjä, T.; Worsnop, D. R.; Ehn, M. et al. Effects of Chemical Complexity on the Autoxidation Mechanisms of Endocyclic Alkene Ozonolysis Products: From Methylcyclohexenes toward Understanding aPinene. J. Phys. Chem. A 2015, 119, 4633-4650.

(23) Kurtéen, T.; Tiusanen, K.; Roldin, P.; Rissanen, M.; Luy, J.-N.; Boy, M.; Ehn, M.; Donahue, N. $\alpha$-Pinene Autoxidation Products May Not Have Extremely Low Saturation Vapor Pressures Despite High O:C Ratios. J. Phys. Chem. A 2016, 120, 2569-2582.

(24) Malm, W. C.; Day, D. E. Estimates of Aerosol Species Scattering Characteristics as a Function of Relative Humidity. Atmos. Environ. 2001, 35, 2845-2860.

(25) Bilde, M.; Svenningsson, B. CCN Activation of Slightly Soluble Organics: The Importance of Small Amounts of Inorganic Salt and Particle Phase. Tellus B 2004, 56, 128-134.

(26) Cruz, C. N.; Pandis, S. N. A Study of the Ability of Pure Secondary Organic Aerosol to Act as Cloud Condensation Nuclei. Atmos. Environ. 1997, 31, 2205-2214.

(27) Berkemeier, T.; Shiraiwa, M.; Pöschl, U.; Koop, T. Competition between Water Uptake and Ice Nucleation by Glassy Organic Aerosol Particles. Atmos. Chem. Phys. 2014, $14,12513-12531$.

(28) Nadykto, A. B.; Yu, F. Strong Hydrogen Bonding between Atmospheric Nucleation Precursors and Common Organics. Chem. Phys. Lett. 2007, 435, 14-18.

(29) Xu, W.; Zhang, R. A Theoretical Study of Hydrated Molecular Clusters of Amines and Dicarboxylic Acids. J. Chem. Phys. 2013, 139, 064312. 
(30) Zhu, Y.; Liu, Y.; Huang, T.; Jiang, S.; Xu, K.; Wen, H.; Zhang, W.; Huang, W. Theoretical Study of the Hydration of Atmospheric Nucleation Precursors with Acetic Acid. J. Phys. Chem. A 2014, 118, 7959-7974.

(31) Xu, Y.; Nadykto, A. B.; Yu, F.; Jiang, L.; Wang, W. Formation and Properties of Hydrogen-bonded Complexes of Common Organic Oxalic Acid with Atmospheric Nucleation Precursors. J mol. Struc.-THEOCHEM 2010, 951, 28-33.

(32) Weber, K. H.; Morales, F. J.; Tao, F. Theoretical Study on the Structure and Stabilities of Molecular Clusters of Oxalic Acid with Water. J. Phys. Chem. A 2012, 116, 1160111617.

(33) Weber, K. H.; Liu, Q.; Tao, F.-M. Theoretical Study on Stable Small Clusters of Oxalic Acid with Ammonia and Water. J. Phys. Chem. A 2014, 118, 1451-1468.

(34) Miao, S.-K.; Jiang, S.; Chen, J.; Ma, Y.; Zhu, Y.-P.; Wen, Y.; Zhang, M.-M.; Huang, W. Hydration of a Sulfuric Acid-oxalic Acid Complex: Acid Dissociation and its Atmospheric Implication. $R S C A d v$. 2015, 5, 48638-48646.

(35) Chen, J.; Jiang, S.; Liu, Y.-R.; Huang, T.; Wang, C.-Y.; Miao, S.-K.; Wang, Z.-Q.; Zhang, Y.; Huang, W. Interaction of Oxalic Acid with Dimethylamine and its Atmospheric Implications. $R S C A d v . \mathbf{2 0 1 7}$, 7, 6374-6388.

(36) Hu, Y.-C.; Zhang, X.-H.; Li, Q.-S.; Zhang, Y.-H.; Li, Z.-S. Effect of Water on the Structure and Stability of Hydrogen-Bonded Oxalic Acid Dimer. Chem. Phys. Chem. 2017, 18, 3375-3383.

(37) Kildgaard, J. V.; Mikkelsen, K. V.; Bilde, M.; Elm, J. Hydration of Atmospheric Molecular Clusters: A New Method for Systematic Configurational Sampling. J. Phys. Chem. A 2018, 122, 5026-5036. 
(38) Zardini, A. A.; Sjogren, S.; Marcolli, C.; Krieger, U. K.; Gysel, M.; Weingartner, E.; Baltensperger, U.; Peter, T. A Combined Particle Trap/HTDMA Hygroscopicity Study of Mixed Inorganic/Organic Aerosol Particles. Atmos. Chem. Phys. 2008, 8, 5589-5601.

(39) Gaussian 09, Revision E.01, M. J. Frisch, G. W. Trucks, H. B. Schlegel, G. E. Scuseria, M. A. Robb, J. R. Cheeseman, G. Scalmani, V. Barone, B. Mennucci, G. A. Petersson, et al., Gaussian, Inc., Wallingford CT, 2013.

(40) Stewart, J. J. P. Optimization of Parameters for Semiempirical Methods. V. Modification of NDDO Approximations and Application to 70 Elements. J. Molec. Modeling 2007, 13, 1173-1213.

(41) Chai, J.-D.; Head-Gordon, M. Long-range Corrected Hybrid Density Functionals with Damped Atom-atom Dispersion Corrections. Phys. Chem. Chem. Phys. 2008, 10, 66156620.

(42) Leverentz, H. R.; Siepmann, J. I.; Truhlar, D. G.; Loukonen, V.; Vehkamäki, H. Energetics of Atmospherically Implicated Clusters Made of Sulfuric Acid, Ammonia, and Dimethyl Amine. J. Phys. Chem. A 2013, 117, 3819-3825.

(43) Elm, J.; Bilde, M.; Mikkelsen, K. V. Assessment of Binding Energies of Atmopsheric Clusters. Phys. Chem. Chem. Phys 2013, 15, 16442-16445.

(44) Elm, J.; Kristensen, K. Basis Set Convergence of the Binding Energies of Strongly Hydrogen-Bonded Atmospheric Clusters. Phys. Chem. Chem. Phys 2017, 19, 11221133.

(45) Elm, J.; Mikkelsen, K. V. Computational Approaches for Efficiently Modelling of Small Atmospheric Clusters. Chem. Phys. Lett. 2014, 615, 26-29.

(46) Myllys, N.; Elm, J.; Kurtén, T. Density Functional Theory Basis Set Convergence of Sulfuric Acid-Containing Molecular Clusters. Comp. Theor. Chem. 2016, 1098, 1-12. 
(47) Riplinger, C.; Neese, F. An Efficient and Near Linear Scaling Pair Natural Orbital Based Local Coupled Cluster Method. J. Chem. Phys. 2013, 138, 034106.

(48) Riplinger, C.; Sandhoefer, B.; Hansen, A.; Neese, F. Natural Triple Excitations in Local Coupled Cluster Calculations with Pair Natural Orbitals. J. Chem. Phys. 2013, 139, 134101.

(49) Neese F., WIREs Comput Mol Sci 2012, 2: 73-78 doi: 10.1002/wcms.81.

(50) Elm, J.; Kurtén, T.; Bilde, M.; Mikkelsen, K. V. Molecular Interaction of Pinic Acid with Sulfuric Acid - Exploring the Thermodynamic Landscape of Cluster Growth. J. Phys. Chem. A 2014, 118, 7892-7900.

(51) Henschel, H.; Navarro, J. C. A.; Yli-Juuti, T.; Kupiainen-Määttä, O.; Olenius, T.; Ortega, I. K.; Clegg, S. L.; Kurtén, T.; Riipinen, I.; Vehkamäki, H. Hydration of Atmospherically Relevant Molecular Clusters: Computational Chemistry and Classical Thermodynamics. J. Phys. Chem. A. 2014, 118, 2599-2611.

(52) Elm, J.; Myllys, N.; Hyttinen, N.; Kurtén, T. Computational Study of the Clustering of a Cyclohexene Autoxidation Product $\mathrm{C}_{6} \mathrm{H}_{8} \mathrm{O}_{7}$ with Itself and Sulfuric Acid. J. Phys. Chem. A 2015, 119, 8414-8421.

(53) Elm, J.; Myllys, N.; Luy, J.; Kurtén, T.; Vehkamäki, H. The Effect of Water and Bases on the Clustering of a Cyclohexene Autoxidation Product $\mathrm{C}_{6} \mathrm{H}_{8} \mathrm{O}_{7}$ with Sulfuric Acid. J. Phys. Chem. A 2016, 120, 2240-2249. 


\section{Graphical TOC Entry}

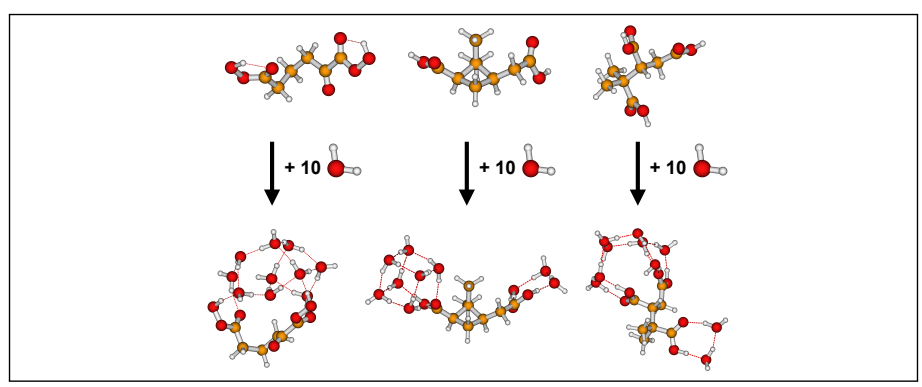

